\title{
Rhodium-Catalyzed Oxidative C-H Allylation of Benzamides with 1,3-Dienes by Allyl-to-Allyl 1,4-Rh(III) Migration
}

\author{
Stamatis E. Korkis, David J. Burns, and Hon Wai Lam* \\ School of Chemistry, University of Nottingham, University Park, Nottingham, NG7 2RD, United Kingdom \\ Supporting Information Placeholder
}

\begin{abstract}
The Rh(III)-catalyzed oxidative C-H allylation of $\mathrm{N}$-acetylbenzamides with 1,3-dienes is described. The presence of allylic hydrogens cis- to the less substituted alkene of the 1,3-diene is important for the success of these reactions. With the assistance of reactions using deuterated 1,3-dienes, a proposed mechanism is provided. The key step is postulated to be the first reported examples of allyl-to-allyl 1,4-Rh(III) migration.
\end{abstract}

\section{INTRODUCTION}

Allylmetal species are important intermediates in organic synthesis. $^{1,2}$ For example, $\pi$-allylmetal species are usually electrophilic, and can be intercepted by diverse nucleophiles in allylic substitutions. ${ }^{1}$ On the other hand, $\sigma$-allylmetal species are usually nucleophilic, and can be employed in a huge range of allylations of $\pi$-electrophiles. ${ }^{2}$ Numerous catalytic, diastereoselective, and/or enantioselective variants of these processes have also been reported.,

A well-recognized feature of allylmetal reactivity is the often facile 1,3-transposition of the metal from one end of the allylic fragment to the other, which potentially enables new bond-forming reactions at either side (Scheme 1, top). Isomerizations of allylmetal species that open up reactions at sites beyond those resulting from conventional 1,3-allylic transposition would be highly enabling for reaction discovery. ${ }^{3,4,5}$ As part of a program in enantioselective rhodium-catalyzed additions of allylboron reagents to imines, ${ }^{3,4,6}$ we have described the allyl-to-allyl 1,4-Rh(I) migration of allylrhodium(I) species (as in $\mathbf{A}$ to $\mathbf{B}$, Scheme 1) ${ }^{4,7}$ This isomerization allows subsequent carbon-carbon bond formation at sites not immediately expected from the structure of the allylboron reagents (Scheme 1, bottom). Given the synthetic potential of this underexplored mode of reactivity, its investigation in other classes of reactions is warranted. In particular, demonstration of metals other than $\mathrm{Rh}(\mathrm{I})$ to engage in allyl-to-allyl 1,4migration would be highly valuable.

\section{Scheme 1. Allylmetal Reactivity}

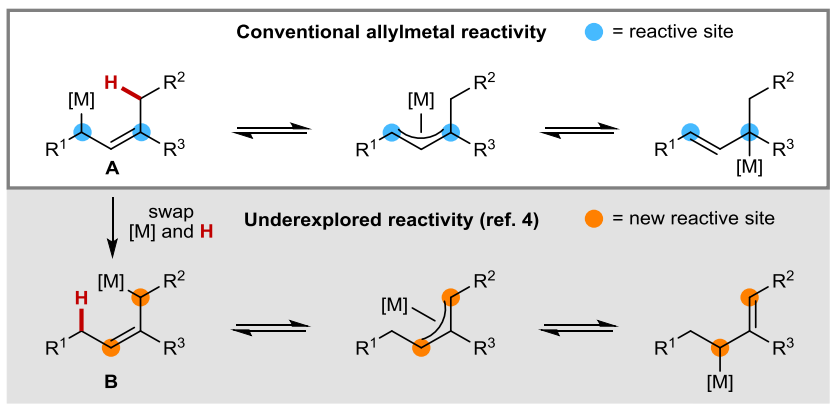

Scheme 2. System to Test Allyl-to-Allyl 1,4-Rh(III) Migration

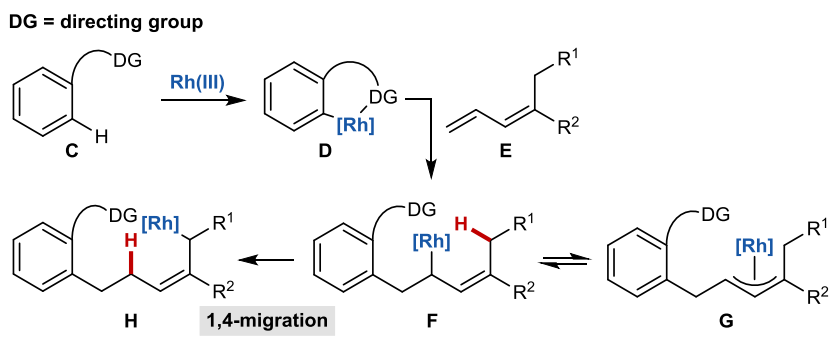

In connection with our work on $\mathrm{Rh}(\mathrm{III})$-catalyzed $\mathrm{C}-\mathrm{H}$ functionalization $^{8,9}$ in combination with alkenyl-to-allyl 1,4$\mathrm{Rh}(\mathrm{III})$ migration to prepare heterocyclic ${ }^{10}$ and carbocyclic ${ }^{11}$ products, we became interested in whether allyl-to-allyl 1,4Rh(III) migrations would be possible. ${ }^{12}$ Our design for investigating the feasibility of this migration is shown in Scheme 2. The directing-group-assisted cyclorhodation of substrate $\mathbf{C}$ with a $\mathrm{Rh}$ (III) complex to give rhodacycle $\mathbf{D}$ is well-known. ${ }^{8}$ Migratory insertion of $\mathbf{D}$ with a 1,3-diene $\mathbf{E}$, which contains allylic hydrogens cis- to the less-substituted alkene, would give allylrhodium species $\mathbf{F}$, which is likely to be in equilibrium with the $\pi$-haptomer $\mathbf{G} .{ }^{13}$ If allyl-to-allyl $1,4-\mathrm{Rh}$ (III) migration of $\mathbf{F}$ were then to occur, a new allylrhodium species $\mathbf{H}$ would form. Although the final fate of $\mathbf{H}$ could not be predicted, this process could serve as a valuable addition to the currently limited number of catalytic $\mathrm{C}-\mathrm{H}$ functionalizations involving 1,3-dienes, ${ }^{14}$ provided that high overall chemo-, regio-, and stereoselectivity is exhibited. Herein, we describe the successful use of allyl-to-allyl 1,4-Rh(III) migration in the oxidative $\mathrm{C}-\mathrm{H}$ allylation of benzamides with 1,3-dienes. These reactions are distinct from other metal-catalyzed $\mathrm{C}-\mathrm{H}$ allylations of arenes, which employ allylic electrophiles, ${ }^{15}$ allenes, ${ }^{16}$ or terminal alkenes ${ }^{17}$ as the reaction partners.

\section{RESULTS AND DISCUSSION}

After attempting $\mathrm{Rh}(\mathrm{III})$-catalyzed reactions of various aromatic substrates of type $\mathbf{C}$ with 1,3-dienes of type $\mathbf{E}$ (see Scheme 2), ${ }^{18}$ we found that $N$-acetylbenzamides $\mathbf{1}$ gave productive reactions under oxidative conditions to form allylation products 3. For example, the reaction of $N$-acetylbenzamide 1a 
Table 1. Scope of the 1,3-Diene ${ }^{a}$
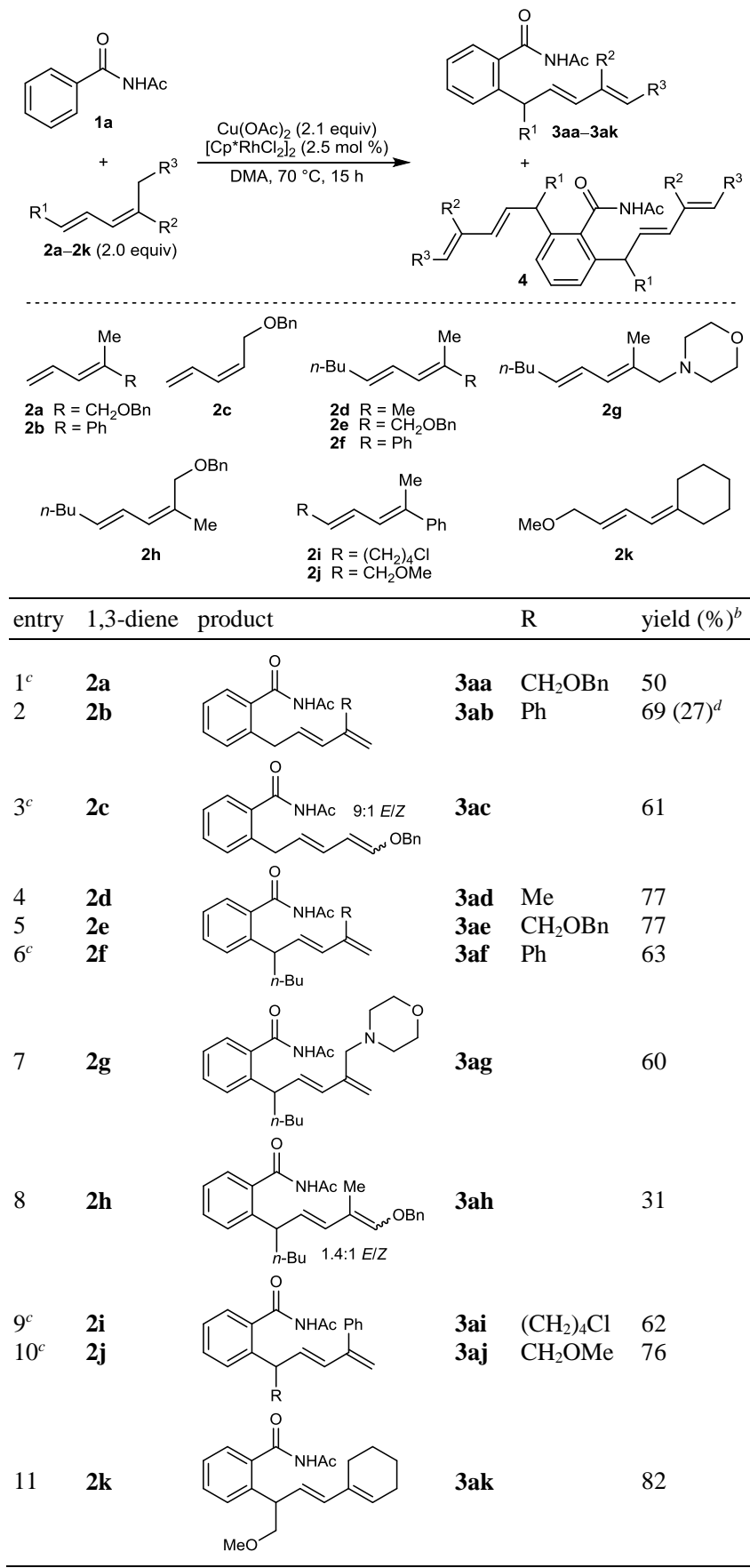

${ }^{a}$ Unless stated otherwise, reactions were conducted using $0.30 \mathrm{mmol}$ of $\mathbf{1 a}$ and $0.60 \mathrm{mmol}$ of $2 .{ }^{b}$ Yield of isolated product. ${ }^{c}$ Conducted using $0.60 \mathrm{mmol}$ of $\mathbf{1 a}$ and $0.30 \mathrm{mmol}$ of $2{ }^{d}$ Values in parentheses refer to the yield of the product 4ab resulting from reaction at both ortho-positions of $\mathbf{1 a}$

with diene $2 \mathbf{a}$ in the presence of $\left[\mathrm{Cp}^{*} \mathrm{RhCl}_{2}\right]_{2}(2.5 \mathrm{~mol} \%)$ and $\mathrm{Cu}(\mathrm{OAc})_{2}\left(2.1\right.$ equiv) in DMA at $70{ }^{\circ} \mathrm{C}$ for $15 \mathrm{~h}$ gave product 3aa in $50 \%$ yield (Table 1 , entry 1 ). Other dienes $\mathbf{2 b - 2 k}$, containing either a methyl or a methylene group cis- to the lesssubstituted alkene, are also effective and gave products 3ab3ak in $31-82 \%$ yield (Table 1, entries 2-11). The mass balance in these reactions was mainly composed of unreacted starting materials. In some cases, a 1:2 ratio of benzamide and diene, respectively, was optimal to maximize the yield of the products 3 (entries 2, 4, 5, 7, 8, and 11). However, in other cases a 2:1 ratio of $\mathbf{1 a : 2}$ was chosen to minimize the formation of products 4 , which result from $\mathrm{C}-\mathrm{H}$ functionalization at both ortho-positions of $\mathbf{1 a}$ (entries 1, 3, 6, 9, and 10). In one reaction, the diallylated product $\mathbf{4 a b}$ was isolated (entry 2). Dienes containing a terminal alkene are effective (entries 1-3), and hydrogen, phenyl, and various alkyl groups at the alkenes are well-tolerated. With $\mathbf{2 a}$, the product 3aa is derived from loss of a hydrogen atom from the methyl substituent cis- to the vinyl group, rather than from the benzyloxymethyl substituent trans- to the vinyl group (entry 1). Diene 2c, which contains a 1,2-disubstituted $Z$-alkene, reacted to give dienol benzyl ether 3ac as a 9:1 mixture of $E / Z$ isomers, along with traces of unidentified decomposition products (entry 3). Dienes $\mathbf{2 d}-\mathbf{2 k}$, which contain a 1,2-disubstituted alkene and a trisubstituted alkene, were also effective (entries 4-11). Here, carboncarbon bond formation occurs exclusively at the 1,2disubstituted alkene, at the carbon distal to the trisubstituted alkene. As with diene 2a (entry 1), when there are different geminal alkyl groups at the trisubstituted alkene, the products are derived from loss of a hydrogen atom at the alkyl group cis- to the disubstituted alkene (entries 4, 5, 7, and 8). This point is further exemplified by the outcomes with dienes $\mathbf{2 e}$ and $\mathbf{2 h}$, which are geometric isomers of each other (entries 5 and 8 ). The reaction with $\mathbf{2 h}$ did not go to completion but dienol benzyl ether 3ah was obtained in $31 \%$ yield as a $1.4: 1$ mixture of $E: Z$ isomers (entry 8). No evidence of 3aa was detected in this reaction.

Attention was then turned to the scope of the reaction with respect to the $N$-acetylbenzamide (Table 2). Benzamides containing a methyl group at the para-, meta-, or ortho-positions (entries 1, 2, 5, and 6) are tolerated, as are those bearing paramethoxy (entry 3) or para-nitro substituents (entry 4). Electron-withdrawing substituents on the aromatic ring of the benzamide appear to be beneficial, as shown by the formation of 3dj in $75 \%$ yield compared with a $46 \%$ yield for $3 \mathbf{c j}$ (compare

Table 2. Scope of the $N$-Acetylbenzamide ${ }^{a}$
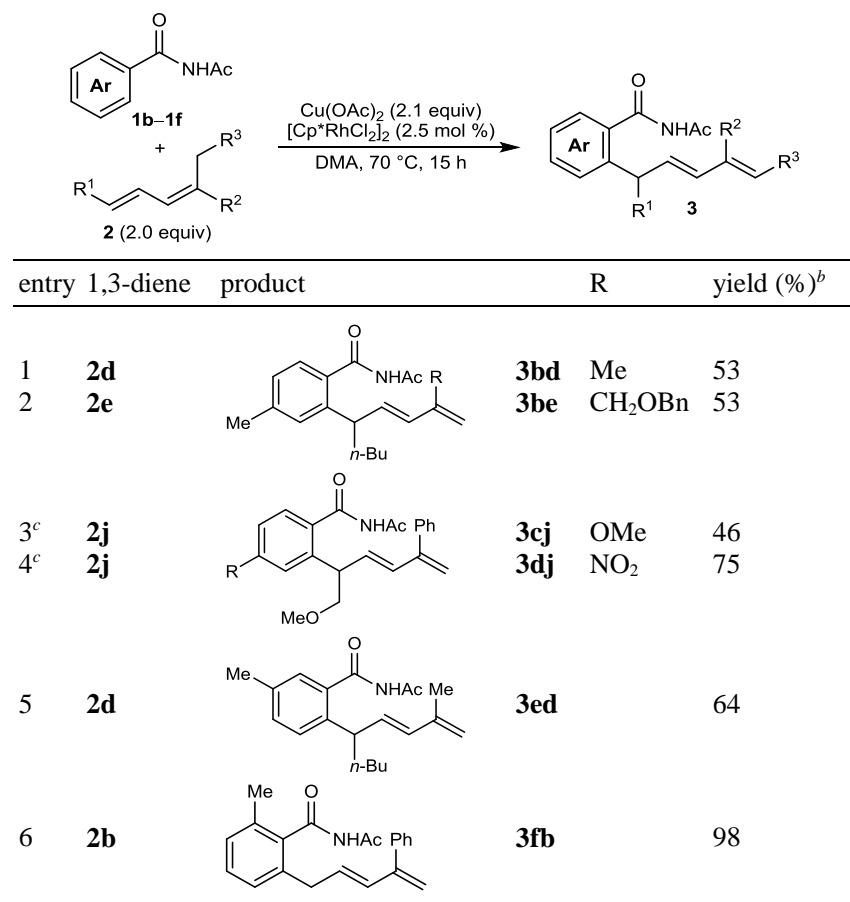

${ }^{a}$ Unless stated otherwise, reactions were conducted using $0.30 \mathrm{mmol}$ of 1 and $0.60 \mathrm{mmol}$ of $2 .{ }^{b}$ Yield of isolated product. ${ }^{c}$ Conducted using $0.60 \mathrm{mmol}$ of $\mathbf{1}$ and $0.30 \mathrm{mmol}$ of $\mathbf{2}$ 


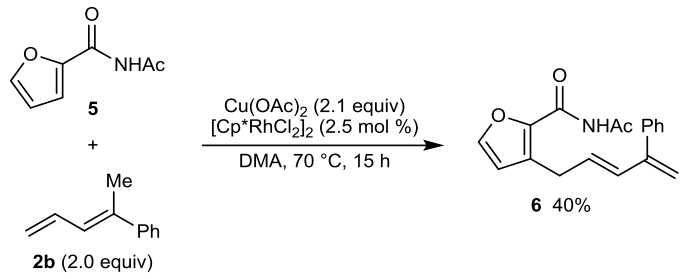

entries 3 and 4). C-H functionalization of a furan-containing substrate $\mathbf{5}$ is also possible, although the yield of the product $\mathbf{6}$ was modest (eq 1).

A possible catalytic cycle for these reactions begins with formation of $\mathrm{Cp}^{*} \mathrm{Rh}(\mathrm{OAc})_{2}$ from $\left[\mathrm{Cp}^{*} \mathrm{RhCl}_{2}\right]_{2}$ and $\mathrm{Cu}(\mathrm{OAc})_{2}$ (Scheme 3), which reacts with $\mathrm{N}$-acetylbenzamide 1a to give rhodacycle 7 and $\mathrm{AcOH}$. Coordination and migratory insertion of 1,3-diene $\mathbf{2 d}$ at the less-substituted alkene gives rhodacycle $\mathbf{8}$, in which there is also an allylrhodium(III) moiety. Acetolysis of $\mathbf{8}$ gives allylrhodium(III) species $\mathbf{9}$, which can undergo 1,4-Rh(III) migration ${ }^{10,11,12}$ to the cis-allylic carbon to give a

Scheme 3. Postulated Catalytic Cycle

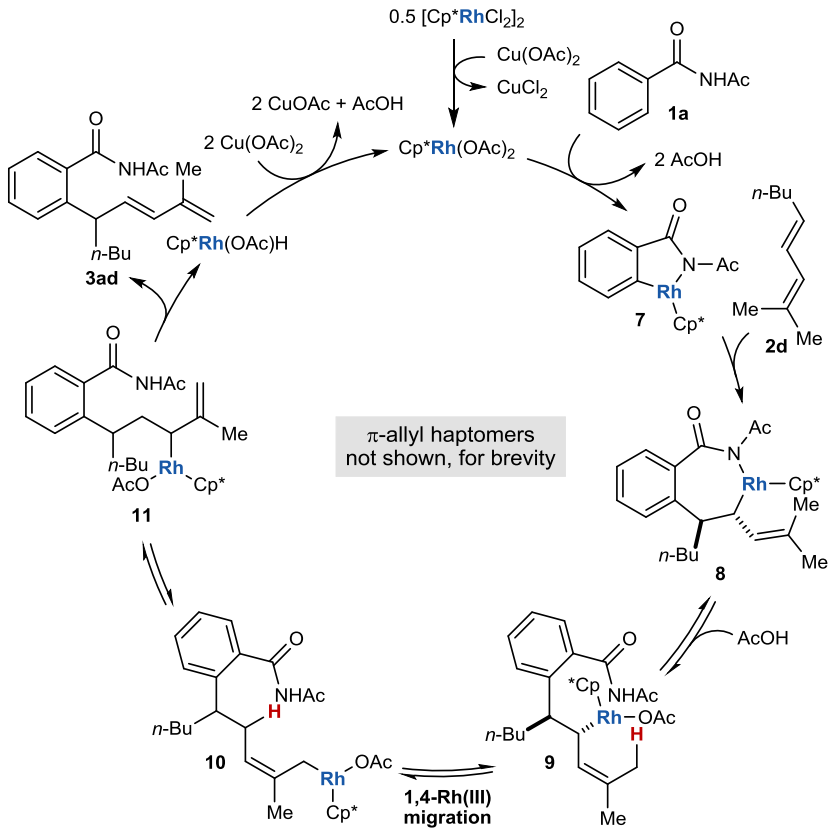

new $\sigma$-allylrhodium intermediate 10. A $\sigma-\pi-\sigma$ isomerization of 10 provides $\sigma$-allylrhodium species $\mathbf{1 1}$, which undergoes $\beta$ hydride elimination to give product 3ad and $\mathrm{Cp}^{*} \mathrm{Rh}(\mathrm{OAc}) \mathrm{H}$. Reaction of $\mathrm{Cp}^{*} \mathrm{Rh}(\mathrm{OAc}) \mathrm{H}$ with $\mathrm{Cu}(\mathrm{OAc})_{2}$ (2.0 equiv) leads to reductive elimination to give $\mathrm{AcOH}$ and $\mathrm{Cp} * \mathrm{Rh}(\mathrm{I})$, which is oxidized to regenerate $\mathrm{Cp}{ }^{*} \mathrm{Rh}(\mathrm{OAc})_{2}$. Although we have proposed the acetolysis of $\mathbf{8}$ into $\mathbf{9}$, we cannot discount the possibility that the directing group remains coordinated to rhodium in one or more of the subsequent intermediates.

An alternative mechanism involves the isomerization of 9

Scheme 4. Alternative Mechanistic Pathway

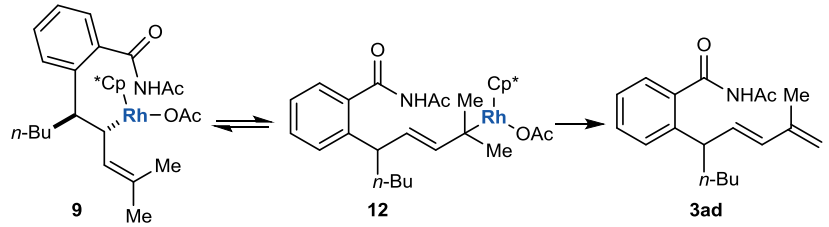

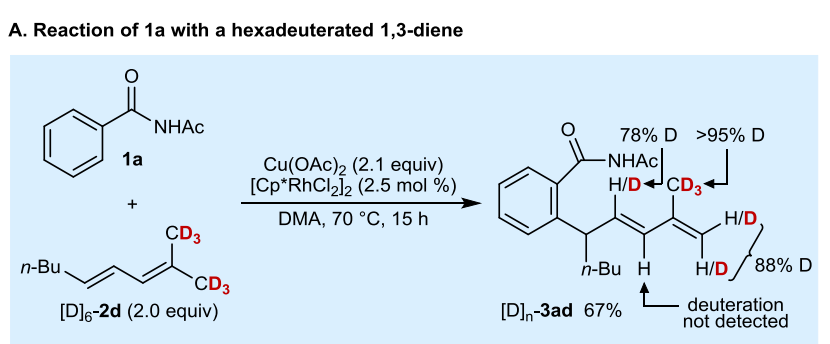

B. Deuterium depletion by $\beta$-deuteride elimination of $[D]_{6}-11 a$

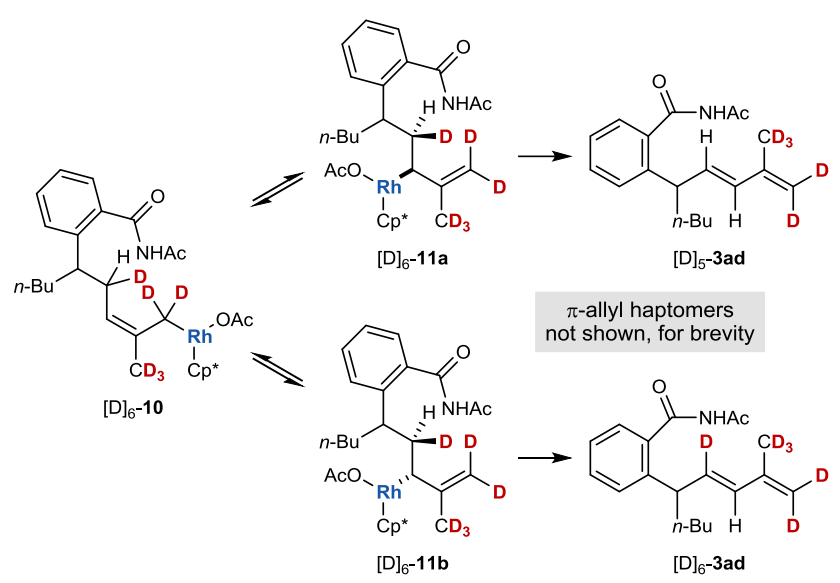

C. Deuterium depletion at the alkenyl methylene

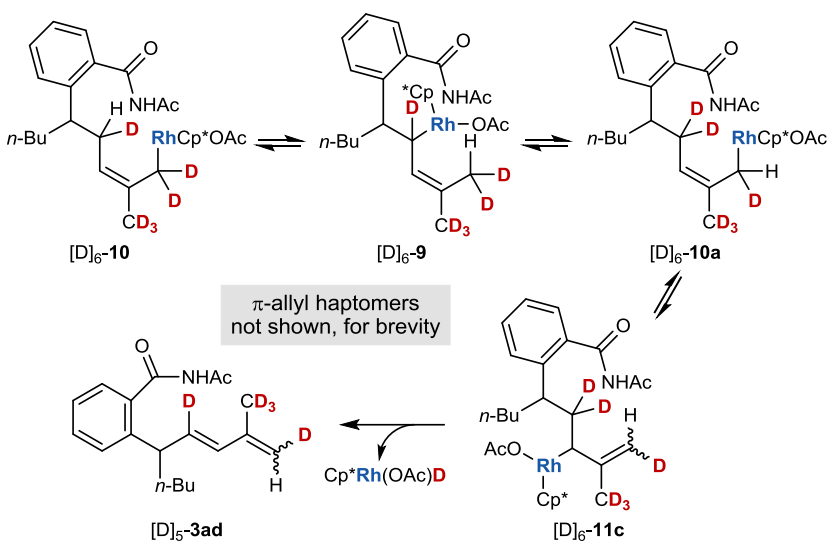

Figure 1. Investigation of deuterium transfer with 1,3-diene [D]63ad and mechanistic rationale.

into $\sigma$-allylrhodium species $\mathbf{1 2}$, which undergoes $\beta$-hydride elimination to give 3ad (Scheme 4). If this mechanism was operative, it would be expected that dienes $2 \mathbf{e}$ and $\mathbf{2 h}$, which differ only in the geometry of the trisubstituted alkene, would react to provide similar outcomes. The fact that different products are obtained in their reactions with 1a (Table 1, entries 5 and 8) suggests this pathway is less likely.

Further support for the mechanism proposed in Scheme 3 is provided by the reaction of $\mathbf{1 a}$ with the hexadeuterated diene $[\mathrm{D}]_{6}-\mathbf{2 d}$ (Figure 1A). This experiment gave $[\mathrm{D}]_{\mathrm{n}}-\mathbf{3 a d}$ in $67 \%$ yield, in which there was significant, but incomplete, deuterium transfer $\left(78 \%\right.$ D) from one of the $\mathrm{CD}_{3}$ groups to the alkenyl carbon proximal to the benzene ring. This outcome may be rationalized by considering that $\sigma-\pi-\sigma$-isomerization of $[D]_{6}-10$ could provide $[D]_{6}-\mathbf{1 1 a}$ or $[\mathrm{D}]_{6}-\mathbf{1 1 b}$ (Figure $1 \mathrm{~B}$ ). Deuterium depletion can then occur by $\beta$-deuteride elimination of $[D]_{6}-11 a$ to give $[D]_{5}-3 a d$, whereas $\beta$-hydride elimination of $[\mathrm{D}]_{6}-\mathbf{1 1 b}$ would give $[\mathrm{D}]_{6}-\mathbf{3 a d}$. 
Another outcome of the experiment shown in Figure 1A is partial deuterium depletion $(88 \% \mathrm{D})$ at the alkenyl methylene of $[D]_{n}-3 a d$. This result may be explained by reversible allylto-allyl 1,4-migration between $[\mathrm{D}]_{6}-\mathbf{1 0},[\mathrm{D}]_{6}-\mathbf{9}$, and $[\mathrm{D}]_{6}-\mathbf{1 0 a}$, which leads to deuterium-hydrogen exchange between the two cis-allylic substituents (Figure 1C). ${ }^{4} \sigma-\pi-\sigma$-Isomerization of $[D]_{6}-10 a$ would provide $[D]_{6}-11 c$, from which $\beta$-deuteride elimination would give $[\mathrm{D}]_{5}-\mathbf{3 a d}$, in which there is deuterium depletion at the alkenyl methylene group.

Regarding the actual mechanism of allyl-to-allyl 1,4-Rh(III) migration, there are a number of possibilities (Scheme 5). First, in a manner similar to that proposed for the alkenyl-toallyl 1,4-Rh(III) migrations we described previously, ${ }^{10,11}$ an acetate-promoted, concerted metalation-deprotonation of $[\mathrm{D}]_{6}$ 9 would give rhodacycle 13, which could undergo acetolysis to give 10. Alternatively, 9 could undergo a $\mathrm{C}-\mathrm{H}$ oxidative addition to give a $\mathrm{Rh}(\mathrm{V})$ hydride species 14 , which can then form 10 by a $\mathrm{C}-\mathrm{H}$ reductive elimination. The participation of $\mathrm{Rh}(\mathrm{V})$ intermediates has been suggested in various other $\mathrm{Rh}(\mathrm{III})$-catalyzed $\mathrm{C}-\mathrm{H}$ functionalization reactions ${ }^{19}$ and has gained some experimental and theoretical support. ${ }^{20}$ Finally, 9 could undergo a $\sigma$-complex-assisted metathesis $(\sigma$ CAM) $)^{12 a, 21,22}$ via $\mathbf{1 5}$ to give $\mathbf{1 0 .}$

\section{Scheme 5. Possible Mechanisms for 1,4-Rh(III) Migration}

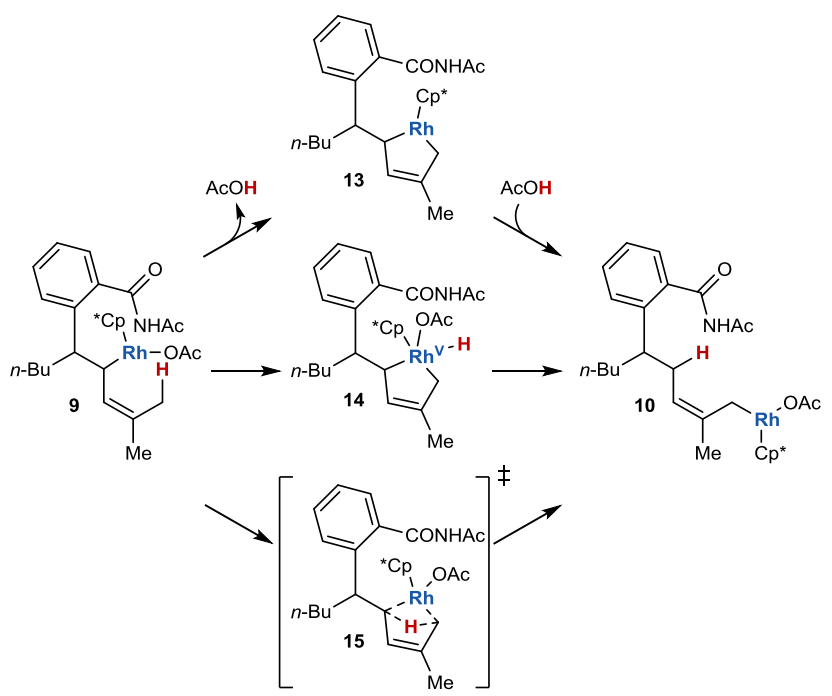

To investigate the possibility of an acetate-assisted concerted metalation-deprotonation pathway to give $\mathbf{1 3}$, the reaction of $\mathrm{N}$-acetylbenzamide 1a with 1,3-diene $\mathbf{2 d}$ was conducted in in a 9:1 mixture of $\mathrm{DMA} / \mathrm{D}_{2} \mathrm{O}$. The presence of $\mathrm{D}_{2} \mathrm{O}$ would be expected to provide some of deuterated 3ad as a result of deuteronolysis of $\mathbf{1 3}$, as we have observed previously in related alkenyl-to-allyl 1,4-Rh(III) migrations. ${ }^{10,11}$ In the event, $\mathrm{D}_{2} \mathrm{O}$ markedly decreased the efficiency of oxidative $\mathrm{C}-\mathrm{H}$ allylation. Nevertheless, 3ad was isolated in $10 \%$ yield but no deuterium incorporation was detected. This result suggests that the intermediacy of $\mathbf{1 3}$ is less likely and that $\mathrm{C}-\mathrm{H}$ oxidative

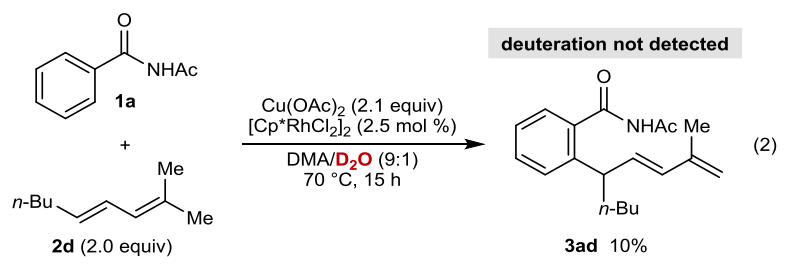

addition/reductive elimination or $\sigma$-CAM pathways may be more probable mechanisms for allyl-to-allyl 1,4-Rh(III) migration.

Thus far, all of the 1,3-dienes tested contain allylic hydrogens cis- to the less-substituted alkene, which enables facile allyl-to-allyl 1,4-Rh(III) migration. To test whether 1,3-dienes lacking this structural feature would also be effective substrates, the reaction of $\mathbf{1 a}$ (2.0 equiv) with 1,3-diene $\mathbf{1 4}$, the $E$ isomer of diene 2c (see Table 1, entry 3 ), was conducted (Figure 2A). This experiment did give allylation product 3ac as a 9:1 mixture of $E / Z$ isomers, but in a much lower yield of $31 \%$ compared with the $61 \%$ yield obtained when the corresponding Z-diene 2c was used (Table 1, entry 3). In addition, alkenylation product $\mathbf{1 5}$ was isolated in $12 \%$ yield, which is notable as analogous alkenylation products were not formed in any of the reactions examined up till this point. The corresponding reaction conducted with dideuterated diene $[\mathrm{D}]_{2}-\mathbf{1 4}$ gave deuterated products $[\mathrm{D}]_{\mathrm{n}}-\mathbf{1 5}$ and $[\mathrm{D}]_{\mathrm{n}}-\mathbf{3 a c}$, each in $16 \%$ yield, in which appreciable 1,4-deuterium transfer was observed (Figure $2 \mathrm{~B}$ ). This time, $[\mathrm{D}]_{\mathrm{n}}-\mathbf{3 a c}$ was obtained as a $6: 1$ mixture of $E / Z$ isomers.
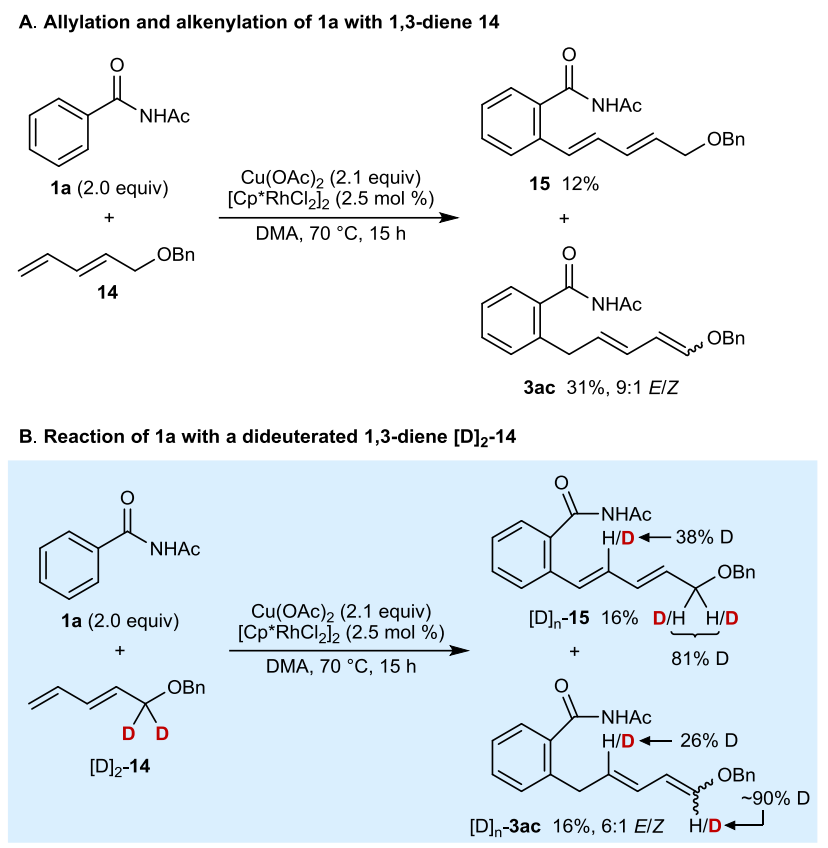

Figure 2. Reaction of a 1,3-diene lacking cis-allylic hydrogens.

The appreciable 1,4-deuterium transfer in both $[D]_{\mathrm{n}}-\mathbf{1 5}$ and $[D]_{n}$-3ac suggests a complex mechanism is operative, involving the interconversion between numerous allylrhodium(III) species by $\sigma-\pi-\sigma$ isomerization (1,3-allylic transposition), $E / Z$ isomerization, and allyl-to-allyl 1,4- $\mathrm{Rh}(\mathrm{III})$ migration pathways (Scheme 6). First, the reaction of 1a, $[D]_{2}-14$, and $\left[\mathrm{Cp} * \mathrm{RhCl}_{2}\right]_{2}$ following the initial steps of the catalytic cycle shown in Scheme 3 leads to the formation of $(E)-\mathbf{1 6 a}$, which can give a dideuterated isomer of alkenylation product $[D]_{n}-\mathbf{1 5}$ by $\beta$-hydride elimination. Intermediate $(E)$-16a can also undergo $\sigma-\pi-\sigma$ isomerization into $(E)-\mathbf{1 7} \mathbf{a}$, which, after $\beta$ deuteride elimination, would give a monodeuterated allylation product $[\mathrm{D}]_{\mathrm{n}}-3$ ac. Alternatively, $(E)-\mathbf{1 6 a}$ can undergo $\sigma-\pi-\sigma$ isomerization with concomitant $E / Z$ isomerization to give (Z)16a, from which a series of reversible allyl-to-allyl 1,4-Rh(III) migrations involving either a 1,4-deuterium or a 1,4-hydrogen shift can give new allylrhodium(III) species $(Z)-\mathbf{1 8 a},(Z)-\mathbf{1 6 b}$, 
Scheme 6. Mechanistic Rationale to Explain the Outcome of the Reaction of $1 \mathrm{a}$ with $[\mathrm{D}]_{2-14}$

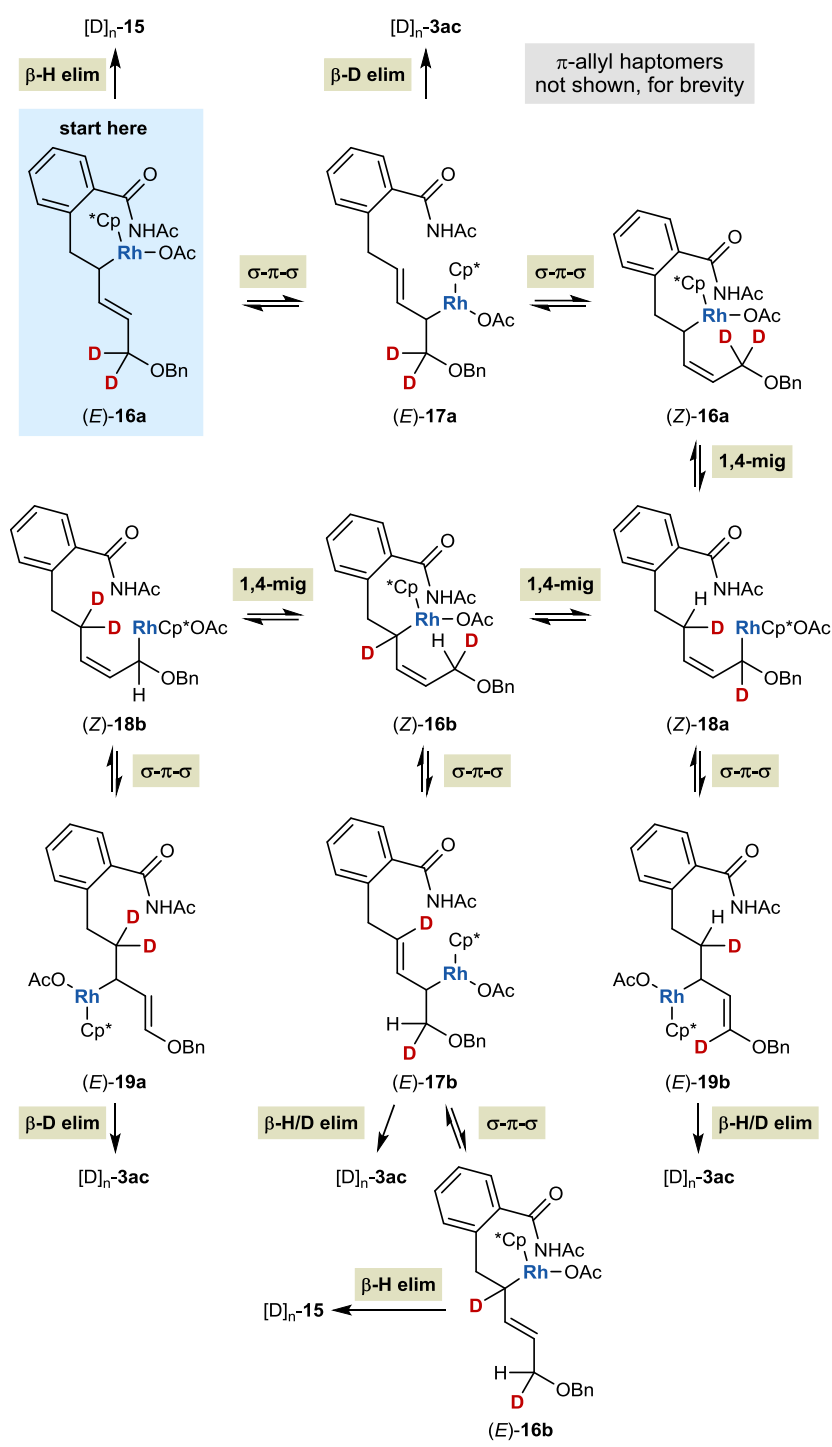

and $(Z)$-18b. These latter three intermediates can undergo $\sigma-\pi$ $\sigma$ isomerization to provide $(E)-\mathbf{1 9 a},(E)-\mathbf{1 7 b}$, and $(E)-\mathbf{1 9 b}$, respectively, from which $\beta$-hydride or $\beta$-deuteride elimination would give various mono- and dideuterated isomers of $[D]_{n^{-}}$ 3ac. Finally, $\sigma-\pi-\sigma$ isomerization of $(E)-\mathbf{1 7 b}$ into $(E)-\mathbf{1 6 b}$ followed by $\beta$-hydride elimination would provide a dideuterated isomer of $[\mathrm{D}]_{\mathrm{n}} \mathbf{- 1 5}$.

To demonstrate the synthetic utility of the allylation products, 1,3-diene 3aa was heated with $N$-phenylmaleimide in toluene at $80{ }^{\circ} \mathrm{C}$ to give Diels-Alder adduct 18 in $67 \%$ yield with >19:1 endo:exo selectivity (eq 3). Furthermore, allylation product 3a reacted smoothly with 1,3-enyne $\mathbf{1 9}$ in a $\mathrm{Rh}(\mathrm{III})$ catalyzed oxidative annulation to give isoindolinone $\mathbf{2 0}$ in $67 \%$ yield (eq 4). In this reaction, 1,3-enyne 19 functions as a one-carbon annulation partner as a result of an alkenyl-to-allyl 1,4-Rh(III) migration. ${ }^{10}$
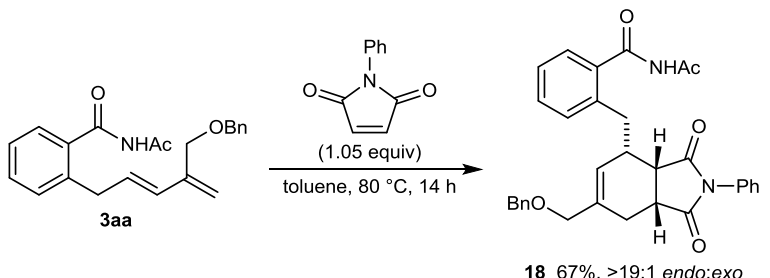

(3)

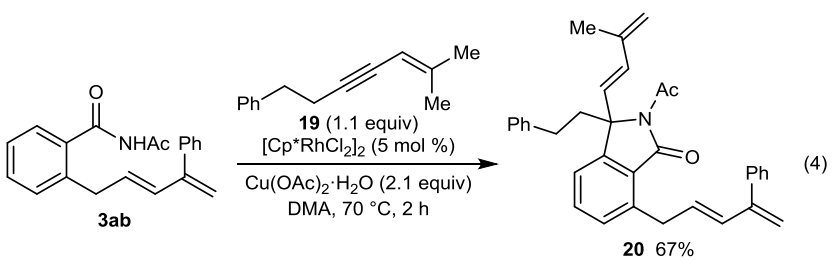

\section{CONCLUSION}

In summary, we have described the oxidative $\mathrm{C}-\mathrm{H}$ allylation of $\mathrm{N}$-acetylbenzamides with 1,3-dienes, which involve, to our knowledge, the first reported examples of allyl-to-allyl 1,4-Rh(III) migration. This new mode of $\mathrm{Rh}(\mathrm{III})$ reactivity enables reaction at sites not available from conventional 1,3allylic transposition. The results of reactions of deuterated 1,3dienes indicate that reversible interconversion of numerous allylrhodium(III) species by $\sigma-\pi-\sigma$ isomerization, $E / Z$ isomerization, and allyl-to-allyl 1,4-Rh(III) migration pathways occurs on timescales that are rapid compared to product-forming $\beta$-hydride (or $\beta$-deuteride) elimination steps. This work suggests that the possibility that these isomerization processes might occur should be taken into consideration in any future design of new reactions involving allylrhodium(III) species. Further investigation of the synthetic potential of allyl-to-allyl 1,4-metal migrations is ongoing in our group.

\section{ASSOCIATED CONTENT}

\section{Supporting Information}

The Supporting Information is available free of charge on the ACS Publications website.

Experimental procedures and full spectroscopic data for all new compounds

\section{AUTHOR INFORMATION}

\section{Corresponding Author}

*hon.lam@nottingham.ac.uk

\section{Notes}

The authors declare no competing financial interest.

\section{ACKNOWLEDGMENTS}

We thank the ERC (Starting Grant No. 258580), EPSRC (Leadership Fellowship to H.W.L.; grants EP/I004769/1 and

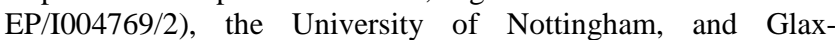
oSmithKline for support of this work. We are grateful to Dr. Ross Denton (University of Nottingham) for a generous donation of LiAlD 4 . 


\section{REFERENCES}

(1) For selected reviews on metal-catalyzed enantioselective allylic substitutions, see: (a) Zhuo, C.-X.; Zheng, C.; You, S.-L. Acc. Chem. Res. 2014, 47, 2558-2573. (b) Tosatti, P.; Nelson, A.; Marsden, S. P. Org. Biomol. Chem. 2012, 10, 3147-3163. (c) Hartwig, J. F.; Stanley, L. M. Acc. Chem. Res. 2010, 43, 1461-1475. (d) Lu, Z.; Ma, S. Angew. Chem., Int. Ed. 2008, 47, 258-297. (e) Helmchen, G.; Dahnz, A.; Dubon, P.; Schelwies, M.; Weihofen, R. Chem. Commun. 2007, 675-691. (f) Trost, B. M.; Crawley, M. L. Chem. Rev. 2003, 103, 2921-2944. (g) Lautens, M.; Fagnou, K.; Hiebert, S. Acc. Chem. Res. 2002, 36, 48-58. (h) Trost, B. M.; Van Vranken, D. L. Chem. Rev. 1996, $96,395-422$.

(2) For selected reviews on metal-catalyzed enantioselective nucleophilic allylations, see: (a) Ketcham, J. M.; Shin, I.; Montgomery, T. P.; Krische, M. J. Angew. Chem., Int. Ed. 2014, 53, 9142-9150. (b) Dechert-Schmitt, A.-M. R.; Schmitt, D. C.; Gao, X.; Itoh, T.; Krische, M. J. Nat. Prod. Rep. 2014, 31, 504-513. (c) Huo, H.-X.; Duvall, J. R.; Huang, M.-Y.; Hong, R. Org. Chem. Front. 2014, 1, 303-320. (d) Yus, M.; González-Gómez, J. C.; Foubelo, F. Chem. Rev. 2011, 111 , 7774-7854. (e) Kobayashi, S.; Mori, Y.; Fossey, J. S.; Salter, M. M. Chem. Rev. 2011, 111, 2626-2704. (f) Denmark, S. E.; Fu, J. Chem. Rev. 2003, 103, 2763-2794.

(3) Martínez, J. I.; Smith, J. J.; Hepburn, H. B.; Lam, H. W. Angew. Chem., Int. Ed. 2016, 55, 1108-1112.

(4) Hepburn, H. B.; Lam, H. W. Angew. Chem., Int. Ed. 2014, 53, 11605-11610.

(5) (a) Xue, P.; Bi, S.; Sung, H. H. Y.; Williams, I. D.; Lin, Z.; Jia, G. Organometallics 2004, 23, 4735-4743. (b) Takada, Y.; Hayashi, S.; Hirano, K.; Yorimitsu, H.; Oshima, K. Org. Lett. 2006, 8, 25152517. (c) Sumida, Y.; Takada, Y.; Hayashi, S.; Hirano, K.; Yorimitsu, H.; Oshima, K. Chem. Asian. J. 2008, 3, 119-125. (d) Omura, S.; Fukuyama, T.; Horiguchi, J.; Murakami, Y.; Ryu, I. J. Am. Chem. Soc. 2008, 130, 14094-14095. (e) Smejkal, T.; Han, H.; Breit, B.; Krische, M. J. J. Am. Chem. Soc. 2009, 131, 10366-10367.

(6) (a) Luo, Y.; Hepburn, H. B.; Chotsaeng, N.; Lam, H. W. Angew. Chem., Int. Ed. 2012, 51, 8309-8313. (b) Hepburn, H. B.; Chotsaeng, N.; Luo, Y. F.; Lam, H. W. Synthesis 2013, 45, 26492661.

(7) For reviews of 1,4-metal migration, see: (a) Ma, S.; Gu, Z. Angew. Chem., Int. Ed. 2005, 44, 7512-7517. (b) Shi, F.; Larock, R. C. Top. Curr. Chem. 2010, 292, 123-164.

(8) For reviews of $\mathrm{Rh}(\mathrm{III})$-catalyzed $\mathrm{C}-\mathrm{H}$ functionalization, see: (a) Song, G.; Li, X. Acc. Chem. Res. 2015, 48, 1007-1020. (b) Kuhl, N.; Schröder, N.; Glorius, F. Adv. Synth. Catal. 2014, 356, 1443-1460. (c) Patureau, F. W.; Wencel-Delord, J.; Glorius, F. Aldrichimica Acta 2012, 45, 31-41. (d) Satoh, T.; Miura, M. Chem. Eur. J. 2010, 16, $11212-11222$.

(9) For selected recent reviews of catalytic C-H functionalization, see: (a) Chen, Z.; Wang, B.; Zhang, J.; Yu, W.; Liu, Z.; Zhang, Y. Org. Chem. Front. 2015, 2, 1107-1295. (b) Gandeepan, P.; Cheng, C.H. Chem. Asian. J. 2015, 10, 824-838. (c) Mo, J.; Wang, L.; Liu, Y.; Cui, X. Synthesis 2015, 47, 439-459. (d) Shi, G.; Zhang, Y. Adv. Synth. Catal. 2014, 356, 1419-1442. (e) Kuhl, N.; Schröder, N.; Glorius, F. Adv. Synth. Catal. 2014, 356, 1443-1460. (f) De Sarkar, S.; Liu, W.; Kozhushkov, S. I.; Ackermann, L. Adv. Synth. Catal. 2014, 356, 1461-1479. (g) Engle, K. M.; Yu, J.-Q. J. Org. Chem. 2013, 78, 8927-8955. (h) Engle, K. M.; Mei, T.-S.; Wasa, M.; Yu, J.Q. Acc. Chem. Res. 2012, 45, 788-802. (i) Yeung, C. S.; Dong, V. M. Chem. Rev. 2011, 111, 1215-1292. (j) Wencel-Delord, J.; Droege, T.; Liu, F.; Glorius, F. Chem. Soc. Rev. 2011, 40, 4740-4761. (k) Ackermann, L. Chem. Rev. 2011, 111, 1315-1345.

(10) Burns, D. J.; Lam, H. W. Angew. Chem., Int. Ed. 2014, 53, 9931-9935.

(11) Burns, D. J.; Best, D.; Wieczysty, M. D.; Lam, H. W. Angew. Chem., Int. Ed. 2015, 54, 9958-9962.

(12) For stoichiometric 1,4-rhodium(III) migration, see: (a) Ikeda, Y.; Takano, K.; Kodama, S.; Ishii, Y. Chem. Commun. 2013, 49,
11104-11106. (b) Ikeda, Y.; Takano, K.; Waragai, M.; Kodama, S.; Tsuchida, N.; Takano, K.; Ishii, Y. Organometallics 2014, 33, 21422145.

(13) For the isolation and characterization of $\pi$-allylrhodium(III) species, see: Shibata, Y.; Kudo, E.; Sugiyama, H.; Uekusa, H.; Tanaka, K. Organometallics 2016, 35, 1547-1552.

(14) For examples of catalytic $\mathrm{C}-\mathrm{H}$ functionalization reactions involving 1,3-dienes, see: (a) Houlden, C. E.; Bailey, C. D.; Ford, J. G.; Gagné, M. R.; Lloyd-Jones, G. C.; Booker-Milburn, K. I. J. Am. Chem. Soc. 2008, 130, 10066-10067. (b) Li, Q.; Yu, Z.-X. J. Am. Chem. Soc. 2010, 132, 4542-4543. (c) Li, Q.; Yu, Z.-X. Angew. Chem., Int. Ed. 2011, 50, 2144-2147. (d) Nishimura, T.; Ebe, Y.; Hayashi, T. J. Am. Chem. Soc. 2013, 135, 2092-2095. (e) Nishimura, T.; Nagamoto, M.; Ebe, Y.; Hayashi, T. Chem. Sci. 2013, 4, 44994504. (f) Zhao, D.; Lied, F.; Glorius, F. Chem. Sci. 2014, 5, 28692873. (g) Khan, I.; Chidipudi, S. R.; Lam, H. W. Chem. Commun. 2015, 51, 2613-2616. (h) Cooper, S. P.; Booker-Milburn, K. I. Angew. Chem., Int. Ed. 2015, 54, 6496-6500.

(15) For examples of metal-catalyzed $\mathrm{C}-\mathrm{H}$ allylation of arenes with allylic electrophiles, see: (a) Oi, S.; Tanaka, Y.; Inoue, Y. Organometallics 2006, 25, 4773-4778. (b) Tsai, A. S.; Brasse, M.; Bergman, R. G.; Ellman, J. A. Org. Lett. 2011, 13, 540-542. (c) Kuninobu, Y.; Ohta, K.; Takai, K. Chem. Commun. 2011, 47, 1079110793. (d) Yao, T.; Hirano, K.; Satoh, T.; Miura, M. Angew. Chem. Int. Ed. 2011, 50, 2990-2994. (e) Fan, S.; Chen, F.; Zhang, X. Angew. Chem., Int. Ed. 2011, 50, 5918-5923. (f) Makida, Y.; Ohmiya, H.; Sawamura, M. Angew. Chem., Int. Ed. 2012, 51, 4122-4127. (g) Wang, H.; Schröder, N.; Glorius, F. Angew. Chem., Int. Ed. 2013, 52 , 5386-5389. (h) Asako, S.; Ilies, L.; Nakamura, E. J. Am. Chem. Soc. 2013, 135, 17755-17757. (i) Cong, X.; Zeng, X. Org. Lett. 2014, 16, 3716-3719. (j) Suzuki, Y.; Sun, B.; Sakata, K.; Yoshino, T.; Matsunaga, S.; Kanai, M. Angew. Chem., Int. Ed. 2015, 54, 99449947. (k) Gensch, T.; Vasquez-Cespedes, S.; Yu, D.-G.; Glorius, F. Org. Lett. 2015, 17, 3714-3717. (1) Cera, G.; Haven, T.; Ackermann, L. Angew. Chem., Int. Ed. 2016, 55, 1484-1488.

(16) For examples of metal-catalyzed directing-group assisted C-H allylation of arenes with allenes, see: (a) Zhang, Y. J.; Skucas, E.; Krische, M. J. Org. Lett. 2009, 11, 4248-4250. (b) Zeng, R.; Fu, C.; Ma, S. J. Am. Chem. Soc. 2012, 134, 9597-9600. (c) Ye, B.; Cramer, N. J. Am. Chem. Soc. 2013, 135, 636-639.

(17) (a) Takahama, Y.; Shibata, Y.; Tanaka, K. Org. Lett. 2016 , 18, 2934-2937. (b) Yamaguchi, T.; Kommagalla, Y.; Aihara, Y.; Chatani, N. Chem. Commun. 2016, 52, 10129-10132.

(18) See the Supporting Information for details of other substrates evaluated.

(19) (a) Wencel-Delord, J.; Nimphius, C.; Patureau, F. W.; Glorius, F. Angew. Chem., Int. Ed. 2012, 51, 2247-2251. (b) Schröder, N.; Wencel-Delord, J.; Glorius, F. J. Am. Chem. Soc. 2012, 134, 82988301. (c) Ryu, J.; Shin, K.; Park, S. H.; Kim, J. Y.; Chang, S. Angew. Chem., Int. Ed. 2012, 51, 9904-9908. (d) Shin, K.; Baek, Y.; Chang, S. Angew. Chem., Int. Ed. 2013, 52, 8031-8036.

(20) (a) Xu, L.; Zhu, Q.; Huang, G.; Cheng, B.; Xia, Y. J. Org. Chem. 2012, 77, 3017-3024. (b) Park, S. H.; Kwak, J.; Shin, K.; Ryu, J.; Park, Y.; Chang, S. J. Am. Chem. Soc. 2014, 136, 2492-2502. (c) Zhou, T.; Guo, W.; Xia, Y. Chem. Eur. J. 2015, 21, 9209-9218. (d) Li, J.; Qiu, Z. J. Org. Chem. 2015, 80, 10686-10693. (e) Yang, Y.-F.; Houk, K. N.; Wu, Y.-D. J. Am. Chem. Soc. 2016, 138, 6861-6868.

(21) Li, Y.; He, G.; Kantchev, E. A. B. Phys. Chem. Chem. Phys. 2014, 16, 24250-24255.

(22) Perutz, R. N.; Sabo-Etienne, S. Angew. Chem., Int. Ed. 2007, 46, 2578-2592. 


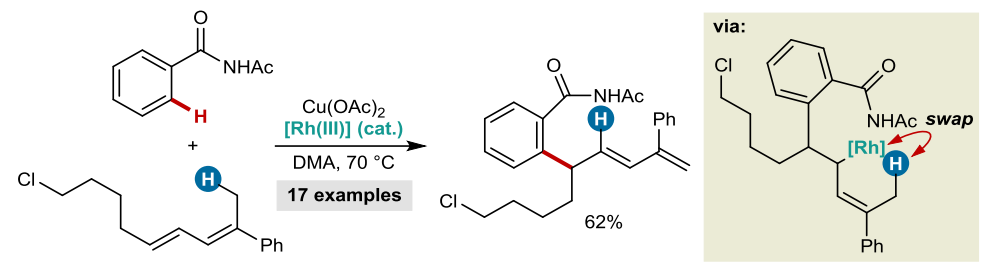

